\title{
BMJ Open Cohort profile: a nationwide cohort of Finnish military recruits born in 1958 to study the impact of lifestyle factors in early adulthood on disease outcomes
}

Jorma Sormunen, ${ }^{1,2}$ Melina Arnold, ${ }^{3}$ Isabelle Soerjomataram, ${ }^{3}$ Eero Pukkala ${ }^{1,4}$

To cite: Sormunen J, Arnold M, Soerjomataram I, et al. Cohort profile: a nationwide cohort of Finnish military recruits born in 1958 to study the impact of lifestyle factors in early adulthood on disease outcomes. BMJ Open 2017;7:e016905. doi:10.1136/ bmjopen-2017-016905

- Prepublication history for this paper is available online To view these files, please visit the journal online (http://dx.doi. org/10.1136/bmjopen-2017016905).

Received 30 March 2017 Revised 13 July 2017 Accepted 10 August 2017

\section{CrossMark}

${ }^{1}$ Faculty of Social Sciences, University of Tampere, Tampere, Finland

${ }^{2}$ Department of Oncology, Tampere University Hospital, Tampere, Finland

${ }^{3}$ Section of Cancer Surveillance, International Agency for Research on Cancer, Lyon, France

${ }^{4}$ Finnish Cancer Registry, Institute for Statistical and Epidemiological Cancer Research, Helsinki, Finland

Correspondence to Dr Jorma Sormunen; jorma.sormunen@gmail.com

\section{ABSTRACT}

Purpose The cohort was set up to study the impact of lifestyle factors in early adulthood on disease outcomes, with a focus on assessing the influence of body composition and physical performance in early adulthood on subsequent cancer risk.

Participants Men born in 1958 who performed their military service between the ages of 17 and 30 years were included in this study $(n=31158)$. They were eligible for military service if they were healthy or had only minor health problems diagnosed at the beginning of their service. Men with chronic illnesses requiring regular medication or treatment were not eligible for service. Comprehensive health data including diagnosed illnesses, anthropometric measures and health behaviour were collected at the beginning and at the end of military service, including data from medical check-ups.

Findings to date During the follow-up, 1124 new cancer cases were diagnosed between baseline (ie, end of the military service for each individual) and end of the year 2014. In the end of the follow-up, $91 \%$ of the study participants were still alive. Overweight (body mass index $(\mathrm{BMI}) \geq 25 \mathrm{~kg} / \mathrm{m}^{2}$ ) and obesity (BMI $\geq 30 \mathrm{~kg} / \mathrm{m}^{2}$ ) were associated with an overall increased risk of cancer. A good or excellent physical condition significantly reduced cancer risk.

Future plans The dataset offers the possibility of linkage with other databases, such as the Finnish Cancer Registry (eg, primary site of the tumour, morphology, time of detection, spreading and primary treatment), vital statistics (date of emigration or deaths), censuses (socioeconomic indicators), hospital discharge data (comorbidity) and population surveys (life habits).

\section{INTRODUCTION}

The Finnish Military Recruits Cohort was set up to study the impact of several lifestyle factors in early adulthood on disease outcomes. Military service in Finland is mandatory for men at the age of $17-30$ years for a period of 8-11 months, meaning that virtually every Finnish man can be traced back in military records. In 2012, we started electronic transcription of the paper-based medical examination records at entry and
Strengths and limitations of this study

- The large number of a proportion-representative sample of men born in 1958 in Finland included in this study.

- A thorough evaluation performed by medical personnel and measurement of different health variables in a uniform manner.

- Possibility for a wide range of linkages with different registries.

- The cohort is not fully representative of the male population born in 1958, which means that the results cannot be fully generalised to the entire population. Those suffering from chronically bad health before military service and those who chose to pursue their national service in civil service for any reason (ethical or religious) were not included in the cohort.

- We only have data from the military conscripts collected during their military service, when their average age was 20 years.

exit of the mandatory military service of all men born in 1958, which was the oldest full dataset available to us. These records contain demographic information, data on common health risk factors such as tobacco smoking or height and weight, measurements of general physical performance, a standard medical examination such as blood pressure, results of basic urine examinations (sugar, proteins, leucocytes, nitrites and bacteria) and eyesight screening tests as well as self-reported health status.

One of the initial aims of this study was to document and assess the influence of early adulthood body composition and physical performance on adult cancer risk. This was motivated by the increasing burden of disease particularly in high-income countries such as Finland that has been linked to the growing proportion of the population with insufficient physical activity and high body weight. Regular physical activity (PA) and a healthy 
body weight have been reported to positively impact general health and have been associated with lower risks of several non-communicable diseases including cardiovascular diseases, ${ }^{1}$ diabetes ${ }^{2}$ and cancer. ${ }^{34}$

In men, regular PA shows sufficient evidence to protect from colorectal cancer. ${ }^{56}$ Similar associations have also been suggested for prostate ${ }^{7-9}$ and bladder cancer, yet evidence is still inconsistent. ${ }^{10}{ }^{11}$ Previous research from Finland has shown that the incidence of cancer among world-class male athletes is reduced when compared with the general population, with the largest risk reduction seen in lung cancer (standardised incidence ratio (SIR) 0.40, 95\% CI: 0.27 to 0.55 ) and kidney cancer (SIR 0.23, 95\% CI: 0.06 to 0.57$).{ }^{12} 13$ As for high body weight, certain cancer sites have been causally linked to body weight, including cancers of the oesophagus (adenocarcinoma), gastric cardia, colorectum, gallbladder, pancreas, liver, breast (postmenopausal), endometrium, ovary, kidney and prostate (non-localised). ${ }^{14}$

Two trained clerks performed the data extraction from paper-based military records (hard copy) into electronic format. The quality of the collected data was continuously monitored both by check-up tools built in the data input programme and by following the summary input statistics.

\section{Cohort description}

The cohort consists of men born in 1958, who served in the Finnish Defence Forces (FDF). There is a universal male conscription in Finland for either military service or civil service, which is usually completed at the age of 20 years. At the time of the service of the cohort in question (entry between 1975 and 1989), men were liable to serve between 240 and 330 days depending on the level of training they were to receive. Of the men born in 1958,

Box List of the variables collected at study entry for each member of the cohort

Personal identity code of the individual

Professional group

- Marital status

- Beginning of military service (date)

- End of military service (date)

- Reason for preliminary discontinuation of military service (diagnosis)

- Duration of military service

- Military service classifications at different stages of the service

- Classification diagnoses at different stages of the military service

- Self-perceived health status at the beginning and at the end of the service

- Height and weight at different stages of the service

- Blood pressure at different stages of the service

- Physical condition test results at different stages of the service Twelve-minute running test results

Muscle strength test results

- Smoking status and amount smoked at different stages of the service

- Use of alcohol and the amount drunken at different stages of the service almost $90 \%$ started their military service, whereas the rest either served in civil service or were completely liberated from the service.

In total, the cohort comprises 31158 men born in 1958 , who were randomly selected from the total population and represent $74 \%$ of all Finnish men born in 1958. The average age at study entry was 20 years (range 17-31 years). In the end of 2014, $91 \%$ of all study participants were still alive.

During their military service, the conscripts were followed-up by healthcare professionals at least twice (at the beginning and at the end of their military service). Their physical condition (PC) was recorded at least once during their military service. Owing to unique person identifiers, record linkage with health and administrative databases allows for a wide range of epidemiological studies on different outcomes in this cohort. Follow-up for incident cancers is currently available until the end of 2014, with annual updates envisaged depending on relevant research questions.

\section{WHAT HAS BEEN MEASURED?}

\section{At the start of military service (baseline)}

All baseline measurements were performed by healthcare professionals (nurses, physicians and dentists) at the beginning of the military service (between 1975 and 1989). After an initial health check, a fitness classification (A-E) was assigned to each conscript, based on his health. Class A indicates good physical and mental health and capability of field service. Men with B-classification were fit for lighter service troops, with health conditions not needing regular treatment or medication, for example, flat foot. C-classified men were liberated from peacetime service, and D-classified men were exempted from military service completely. Men classified as C typically need regular treatment for their condition (eg, diabetes) but are otherwise healthy and can thus be drafted at wartime. D-classified men have a condition that affects their daily life so seriously that they cannot be drafted even during wartime. E-classification means deferment for medical reasons up to 3 years. Diagnoses leading to E-classification are typically young men's adjustment disorders. ${ }^{15}$

After the baseline medical check-up, the basic PC of the conscripts was measured by a $12 \mathrm{~min}$ running test and a test measuring muscle strength. Data on health behaviour (eg, smoking habits and alcohol consumption) were collected during the medical check-ups. A detailed list of all demographic, behavioural and health data items collected at baseline is presented in box. At recruitment, $91.5 \%$ of the men were healthy (classified to service class A), and $7.1 \%$ had minor health problems (service class B) (table 1). In addition, 411 men were classified to service classes C, D or E before the end of the military service (beginning of the follow-up). The majority of all men had a normal weight at recruitment (body mass index, BMI $\left.18.5-25 \mathrm{~kg} / \mathrm{m}^{2}\right), 10.6 \%$ were overweight $\left(\mathrm{BMI} 25-30 \mathrm{~kg} / \mathrm{m}^{2}\right)$ and $1.4 \%$ were obese $(\mathrm{BMI}>30 \mathrm{~kg} /$ 
Table 1 Cohort characteristics at study entry $(n=31158)$

n

$\%$

\begin{tabular}{lrr}
\hline Service classification & & \\
A (healthy) & 28520 & 91.5 \\
B (minor health problems) & 2227 & 7.1 \\
C or D & 192 & 0.6 \\
Missing & 219 & 0.7
\end{tabular}

Smoking status

\begin{tabular}{|rrr} 
Yes & 10707 & 34.4 \\
\hline No & 16066 & 51.6 \\
Missing & 4385 & 14.1 \\
\hline
\end{tabular}

Cigarettes/day among smokers

\begin{tabular}{|c|c|c|}
\hline$<10$ cigarettes/day & 2010 & 18.8 \\
\hline 10-19 cigarettes/day & 5657 & 52.8 \\
\hline$\geq 20$ cigarettes/day & 2862 & 26.7 \\
\hline Missing & 178 & 1.7 \\
\hline \multicolumn{3}{|l|}{ Alcohol consumption } \\
\hline Yes & 19052 & 61.1 \\
\hline No & 8097 & 26.0 \\
\hline Missing & 4009 & 12.9 \\
\hline \multicolumn{3}{|l|}{$\mathrm{BMI}$} \\
\hline Underweight (BMI <18.5) & 1489 & 4.8 \\
\hline Normal weight $(18.5 \leq \mathrm{BMI}<25)$ & 25939 & 83.2 \\
\hline Overweight $(25 \leq \mathrm{BMI}<30)$ & 3294 & 10.6 \\
\hline Obesity (BMI $\geq 30$ ) & 421 & 1.4 \\
\hline Missing & 15 & 0.0 \\
\hline \multicolumn{3}{|l|}{ Body surface area } \\
\hline$<2 \mathrm{~m}^{2}$ & 26729 & 85.8 \\
\hline$\geq 2 \mathrm{~m}^{2}$ & 4415 & 14.2 \\
\hline Missing & 14 & 0.0 \\
\hline \multicolumn{3}{|l|}{ Overall PC } \\
\hline Bad & 1326 & 4.3 \\
\hline Satisfying & 6294 & 20.2 \\
\hline Good & 12707 & 40.8 \\
\hline Excellent & 5503 & 17.7 \\
\hline Missing & 5328 & 17.1 \\
\hline \multicolumn{3}{|l|}{$\mathrm{BMI}$ and PC cross-category } \\
\hline BMI $<25$ and good/excellent PC & 16930 & 54.3 \\
\hline $\mathrm{BMI} \geq 25$ and good/excellent PC & 1277 & 4.1 \\
\hline BMI <25 and bad/satisfying PC & 6001 & 19.3 \\
\hline $\mathrm{BMI} \geq 25$ and $\mathrm{bad} /$ satisfying PC & 1618 & 5.2 \\
\hline Missing & 5332 & 17.1 \\
\hline
\end{tabular}

BMI, body mass index; PC, physical condition.

$\mathrm{m}^{2}$ ). Overall PC was excellent in $17.7 \%$, good in $40.8 \%$ and satisfactory or bad in $24.5 \%$. Most men with BMI $<25$ were also in a good or excellent PC, whereas the overweight and obese men (BMI $\geq 25)$ were more likely to be in a satisfactory or bad PC. Overall, $51.6 \%$ of the men were non-smokers, and $26.0 \%$ stated at the beginning of their military service that they did not consume any alcohol. The number of men in service classes $\mathrm{C}$ and $\mathrm{D}$ was small so these data are not separately reported.

\section{At the end of military service}

Typically, assessments of PC take place at least twice during the military service of each conscript, including medical check-ups at the beginning and at the end of military service. The medical check-up at the end of military service has the same elements as the check-up at the beginning even though it is usually not as rigorously followed as the medical check-up at the beginning. This is because self-perceived health is considered the most important health indicator at the end of the service, only significant changes in this indicator lead to a rigorous medical check-up.

\section{Follow-up via record linkage}

After a complete transcription of the military records, the cohort data were linked with the Finnish Cancer Registry (FCR); National Population Registry (date of emigration or death) and censuses (socioeconomic indicators), hospital discharge data (morbidity) and the cause of death register at Statistics Finland. The linkage required approvals by the FDF and the National Institute of Health and Welfare in Finland. The high-quality FCR data contains information on cancer diagnosis date, type and location of the cancer (topography), morphology, spreading of the cancer and the primary treatment method. ${ }^{16}$

All record linkages were performed using the unique personal identity code (PIC) given to every resident of Finland and used as the key in all registries in Finland. PICs of the men in the cohort collected from the paperbased files were first linked to the Population Registry and checked that every person existed in the population either alive or with date of emigration or death.

In our raw data collection system, we had a built-in mechanism for checking the correct format of the PICs. Only 26 PICs were not found in the population registry. In addition, we had one PIC of wrong gender. These individuals were excluded from the cohort.

\section{Statistical methods}

Cox proportional hazard models with age as underlying time metric were fitted to estimate HRs and 95\% CIs) for the relation between each study variable and the risk of developing malignant cancer by site. Subjects were censored as they emigrated from Finland or died before the end of follow-up (31 December 2014), whichever occurred first. All analyses were carried out using Stata 13.

\section{Results: findings to date}

In this first presentation of this cohort, we demonstrate the linkage that was done with the FCR to obtain data on cancer incidence. We furthermore assessed the 
association between tobacco smoking, alcohol use and anthropometric measures as reported in young adulthood (at study baseline) and cancer risk. All men, except those with a missing service classification $(n=219)$, those with service classification $\mathrm{C}$ or $\mathrm{D}(\mathrm{n}=192)$ and those with a cancer diagnosis before the end of the military service $(n=5)$ were included in the follow-up. The final study sample comprised 30742 men.

During the follow-up, 1124 new cancer cases were diagnosed between baseline (ie, end of the military service for each individual) and end of the year 2014. Study variables were BMI (weight in kilogram divided by height in square metre), overall PC (excellent/good/satisfying/ bad), service classification (A/B), smoking status (yes/ no) and amount (cigarettes/day) and alcohol use (yes/ no).

More than three decades after the end of their military service, this is the first epidemiological assessment of the impact of PC, body composition and certain lifestyle factors (eg, smoking and alcohol consumption), measured in young adulthood, on cancer risk later in life.

Overweight (BMI $\geq 25 \mathrm{~kg} / \mathrm{m}^{2}$ ) and obesity (BMI $\geq 30$ $\mathrm{kgm}^{2}$ ) were associated with an overall increased, but statistically not significant, risk of cancer (age-adjusted HR: $1.08,95 \%$ CI: 0.89 to 1.30 ), a good or excellent PC significantly reduced cancer risk (HR: 0.82, 95\% CI: 0.71 to 0.95$)$. When compared with those with normal weight and good PC, those with normal weight but bad PC had an increased risk of all cancers combined (HR: 1.18, 95\% CI: 1.01 to 1.38 ). Men who were in poor PC and also were overweight had an HR of 1.30 (95\% CI: 1.01 to 1.69) when compared with those with normal weight and good PC. These associations however decreased and became statistically insignificant (respective HRs: 1.05 (95\% CI: 0.88 to 1.26 ) and 1.13 (95\% CI: 0.85 to 1.50$)$ ) when adjusted for smoking, alcohol consumption and service class. Men in service class B were at a more than threefold higher risk of advanced prostate cancer as compared with those in service class A (HR adjusted for age, PC, BMI, smoking and alcohol use: $3.35,95 \%$ CI: 1.14 to 9.90 ).

To further validate health indicators available for this cohort, we also observed a dose-response relationship between the number of cigarettes smoked daily and total cancer incidence. The HR among those who smoked 20 cigarettes or more per day was 1.54 (95\% CI: 1.25 to 1.89). Increased risk was most pronounced for incidence of lung cancer (HR: 9.65, 95\% CI: 4.83 to 19.27).

\section{Main strengths and weaknesses}

The main strength of this study is the large number of a proportion-representative sample of men born in 1958 in Finland included in this study. A thorough evaluation performed by medical personnel and measurement of different health variables including general health and PC were measured in a uniform manner. The FDF have a thorough training protocol for all military and medical personnel especially for classifying service class and to measure PC. Over the 14-year period (1975-1989) during which the men in the cohort completed their service, there were neither new service class classifications nor PC measurement methods introduced in the FDF. We believe that the data we collected from the military records are of high quality.

Situated in Finland, this cohort provides the possibility for a wide range of linkages with different registries. In this first study, we linked the cohort data to the FCR and validated associations with BMI, PC and smoking.

Usually, ill-health seems to be associated with poor PC or high BMI, which in turn are related to some other factors typical with low socioeconomic status (SES). Finland has tried to take steps in order to decrease these risks. Owing to cheap universal health coverage in Finland, all Finns have similar access to healthcare independent of their financial or SES. In addition to this, most Finnish municipalities encourage people to improve their health by physical exercise and by offering planned activities for people of all ages, even people with disabilities.

Some weaknesses should be noted in relation to these data. First, the cohort is not fully representative of the male population born in 1958, which means that the results cannot be fully generalised to the entire population. Those suffering from chronically bad health (eg, development disorders or mental disorders) before military service and those who chose to pursue their national service in civil service for religious, ethical or other reasons were not included in the cohort, but their proportion is small.

Second, we only have data from the military conscripts collected during their military service, lasting between 8 and 11 months. The conscripts were between the ages of 17 and 30 years at the beginning of their military service. We do not have data on the possible changes in their health habits after the completion of their service. Considering the relatively stable life habits in the majority of the population and the long lag related to cancer development, we believe that the changes in the health habits do not markedly confound our results. In the future, linkage with national population survey data, such as the FINRISK study (extensive population study on risk factors behind chronic diseases, whici is carried out by the National Institute for Health and Welfare THL), which is conducted every 5 years since $1972,{ }^{17}$ will allow for better understanding of the magnitude of changes in the risk factors measured during the military service, as well as other risk factors. A marked proportion of the young-age cancers detected up-to-date may have a genetic background which was not taken into account in the present analyses. It is, however, possible to identify first-degree family members of the men in our cohort from the Finnish Population Registry and then link their PICs to the FCR to get information on cancer cases in the family.

At present, the cohort is still relatively young, with moderate number of cancer cases or deaths. However, preliminary results of this cohort show that it can already 
be used for epidemiological purposes and will become even more interesting as the cohort grows older.

Acknowledgements We thank the important work done by Päivi Haapakangas and Anna Kaisa Pasanen, who collected and digitalised the data. Without their work, this study would not be possible.

Contributors JS, EP, MA and IS were responsible for the planning, data collection, data analysis and preparing of the manuscript. All authors have contributed equally. The project has been managed by JS.

Funding This work was supported by a grant of $€ 50000$ from the Finnish Cancer Foundation

Competing interests None declared.

Patient consent Detail has been removed from this case description/these case descriptions to ensure anonymity. The editors and reviewers have seen the detailed information available and are satisfied that the information backs up the case the authors are making.

Provenance and peer review Not commissioned; externally peer reviewed.

Data sharing statement The study data are not freely available due to confidentiality reasons, but the research team welcomes potential collaboration with other researchers. For further information, contact the author EP at the Finnish Cancer Registry (eero.pukkala@cancer.fi) or JS (jorma.sormunen@fimnet.fi).

Open Access This is an Open Access article distributed in accordance with the Creative Commons Attribution Non Commercial (CC BY-NC 4.0) license, which permits others to distribute, remix, adapt, build upon this work non-commercially, and license their derivative works on different terms, provided the original work is properly cited and the use is non-commercial. See: http://creativecommons.org/ licenses/by-nc/4.0/

(c) Article author(s) (or their employer(s) unless otherwise stated in the text of the article) 2017. All rights reserved. No commercial use is permitted unless otherwise expressly granted.

\section{REFERENCES}

1. Vanhees L, De Sutter J, GeladaS N, et al. Importance of characteristics and modalities of physical activity and exercise in defining the benefits to cardiovascular health within the general population: recommendations from the EACPR (Part I). Eur J Prev Cardiol 2012;19:670-86

2. Lamb MJ, Westgate $\mathrm{K}$, Brage $\mathrm{S}$, et al. Prospective associations between sedentary time, physical activity, fitness and cardiometabolic risk factors in people with type 2 diabetes. Diabetologia 2016;59:110-20.

3. Brenner DR. Cancer incidence due to excess body weight and leisure-time physical inactivity in Canada: implications for prevention. Prev Med 2014;66:131-9.

4. de Vries E, Soerjomataram I, Lemmens VE, et al. Lifestyle changes and reduction of colon cancer incidence in Europe: a scenario study of physical activity promotion and weight reduction. Eur $\mathrm{J}$ Cancer 2010;46:2605-16.

5. Boyle T, Keegel T, Bull F, et al. Physical activity and risks of proximal and distal colon cancers: a systematic review and meta-analysis. J Natl Cancer Inst 2012;104:1548-61.

6. Friedenreich CM, Neilson HK, Lynch BM. State of the epidemiological evidence on physical activity and cancer prevention. Eur J Cancer 2010;46:2593-604.

7. De Nunzio C, Presicce F, Lombardo R, et al. Physical activity as a risk factor for prostate cancer diagnosis: a prospective biopsy cohort analysis. BJU Int 2016;117.

8. Johnsen NF, Tjønneland A, Thomsen BL, et al. Physical activity and risk of prostate cancer in the European Prospective Investigation into Cancer and Nutrition (EPIC) cohort. Int J Cancer 2009:125:902-8.

9. Darlington GA, Kreiger N, Lightfoot N, et al. Prostate cancer risk and diet, recreational physical activity and cigarette smoking. Chronic Dis Can 2007;27:145-53.

10. Liu Y, Hu F, Li D, et al. Does physical activity reduce the risk of prostate cancer? A systematic review and meta-analysis. Eur Urol 2011;60:1029-44.

11. Keimling $M$, Behrens $G$, Schmid D, et al. The association between physical activity and bladder cancer: systematic review and metaanalysis. Br J Cancer 2014;110:1862-70.

12. Sormunen J, Bäckmand HM, Sarna S, et al. Lifetime physical activity and cancer incidence-a cohort study of male former elite athletes in Finland. J Sci Med Sport 2014;17:479-84.

13. Pukkala E, Kaprio J, Koskenvuo M, et al. Cancer incidence among Finnish world class male athletes. Int J Sports Med 2000;21:216-20.

14. Anderson AS, Key TJ, Norat T, et al. European code against cancer 4th Edition: obesity, body fatness and cancer. Cancer Epidemiol 2015;39:S34-S45

15. Multimäki P, Parkkola K, Sourander A, et al. Military fitness class of Finnish 18-year-old men-prediction of military fitness class at call-up with the YASR and sociodemographic factors. Soc Psychiatry Psychiatr Epidemiol 2005;40:57-63.

16. Teppo L, Pukkala E, Lehtonen M. Data quality and quality control of a population-based cancer registry. Experience in Finland. Acta Oncol 1994;33:365-9.

17. Borodulin K, Vartiainen $\mathrm{E}$, Peltonen $\mathrm{M}$, et al. Forty-year trends in cardiovascular risk factors in Finland. Eur J Public Health 2015;25:539-46. 